\title{
Intellectual colonialism and national education systems
}

\author{
Svetlana A. Sharonova - Nina V. Trubnikova - Natalya S. Erokhova - \\ Helena A. Nazarova
}

DOI: 10.18355/XL.2018.11.02.27

\begin{abstract}
The concept of intellectual colonialism has recently attracted much attention. Initially, it arose on the basis of a rethinking of the educational processes in the former African colonies of Britain, France, etc. and then acquired a new meaning as a new form of colonization without involving seizure of territories. Further globalization processes accelerated development of this phenomenon and expanded its worldwide influence. Colonial subordination tactics may take various forms. In African countries lacking a well-developed national system of education, intellectual colonialism functions through the introduction of education in the language of the former colonizers of this country. In Eastern Europe, Russia, which have been historically characterized by highly-developed education systems, the effect of intellectual colonialism is manifested in the destruction of these national systems and their subordination to a unified global system rooted in the culture and principles of particular countries (primarily the USA and the UK, which hold leading ranking positions and concentrate financial flows). In countries with a highly-developed economy and stable policy, such as Japan, intellectual colonialism undermines the authority of national education systems through the advancement of world rankings.
\end{abstract}

Key words: colonialism, intellectual colonialism, global system of education, national education

\section{Introduction}

\subsection{The prehistory of intellectual colonialism}

The social phenomenon of colonialism has deep historical roots. Starting from Ancient Rome, colonialism implied various forms of the dependence of the rural population. Here we shall refer to the phenomenon of "colonialism" as political, economic and spiritual enslaving of the peoples of emerging countries by the socially and economically developed states. According to H. Tahsin (2007), colonialism is a political, economic and military strategy of influential states aimed at appropriating the territories, human and material resources of weak societies. Thus, from the beginning of XIII to the middle of XX the Europeans colonized Asian and African regions while killing and exporting the indigenous people.

Quite apart, meanwhile, another type of colonialism was formed, the one which implied obliterating cultural identity of the population in order to make sure that the colonized countries should never reach the level of their economically developed colonizers. That concerned the vast colonies of the British Empire which covered nearly half of the globe; the colonies of France, Spain, Portugal, the Netherlands, Germany, and Belgium on the territory of Africa, Asia, the Americas; the Japanese colonies in Asia. After the 2nd World War, the rise of national-liberating strife prompted the demise of the colonial system which was complete by the 1960-70ies. The liquidation of the colonial system put an end to the territorial division of the world. In 1960 the United Nations took steps to root out colonialism, however, the ex-colonial powers took countermeasures to retain their influence on their former colonies. That was the motive for creating the British Commonwealth by Great Britain and the Francophone Federation by France. The United States joined the club of colonial powers relatively late - that occurred in the period of the Cold War and became known as American imperialism. If, initially the United States based their 
colonialist strategy on the economic subjugation of the counties, then, in the era of neocolonialism, they dramatically changed it, beginning to establish American hegemony over the cultures of third world countries, forming the so-called cultural imperialism.

\subsection{A new form of colonialism - intellectual colonialism}

Analyzing the phenomenon of "intellectual colonialism" from the point of view of politics and philosophy, Yan.Yu. Moiseenko (2017) refers to the theoreticians M. Hardt and A. Negri (2000) who, in their academic work Empire, assert that the traditional "imperialistic" colonialism with its compulsory establishment of parent state institutions of power on the subordinate territories is being replaced by a new version of colonialism - "empire" colonialism. They hold that this new Empire is "devoid of a center or any territorial reference" (Hardt, Negri, 2000).

The concept of intellectual colonialism means cultural and intellectual enslavement of the population. The police of intellectual colonialism are not only directed towards the third world countries but are able to manipulate the cultures of developed countries as well.

In the period of the end of the 20 century to the beginning of the XXI globalization processes have promoted further development and intensification of cultural imperialism. If, in earlier periods, only underdeveloped countries of the third world were subjected to colonization, then, today, there is an hierarchy of cultures being artificially created among developed countries too. In creating the European Union, it tried to not only economically but also culturally withstand the pressure of the United States. The Bologna process acted as an initiator of universalization of the educational sphere of the member countries. It was to ensure high quality education in all the states of the EU. On the one hand, it is an example of self-protection from intellectual colonization on the part of the US; on the other - it has itself become a tool of creating intellectual colonies. The model of the European Higher Education Area has been accepted by the global community and started spreading onto all countries of the world.

In her study of the reactions of Brazilian and German national higher education systems to the global challenges, K. Damm (2015) quotes R. King (2011) who stresses that globalization in the sphere of higher education is characterized by world dominance of certain models and ideas (e.g., administrative reforms regarding new public administration (NPM) which are distributed via social networks and normative pressure (e.g., international ratings). According to R. King (2011), pushing these models into national higher education systems is principally normative and originally includes elements of voluntary acceptance and imitation. The more these models acquire power and legitimacy through distribution, the higher the probability of their acceptance becoming structurally obligatory and involuntary (King, 2011).

While analyzing the inner resistance of Indonesian higher education system to the global challenges, K. Sunarto (2015) notes that Indonesian higher education has been globalized for many decades. According to him, these processes were especially accelerated in 1998 marked by the movement in support of the reform which put an end to the 32-year old authoritarian rule. Since 1998, the new governments have introduced a number of higher education reforms as a response to the challenges of globalization. Within the framework of these reforms, the new governments have ratified international and regional agreements (e.g., The Asian-Pacific Regional Convention of accepting higher education qualifications; the convention of mutual recognition; AFTA); they have introduced new laws and policies which include governmental appeals to higher education institutions urging them to show more initiative in becoming "World Class universities" (Royon, Rahwidiati, 2013).

XLinguae, Volume 11, Issue 2, April 2018, ISSN 1337-8384, eISSN 2453-711X 
In their evaluation of the changes in Estonian higher education system, $\mathrm{K}$. Loogma and U. Meril (2015) draw attention to the fact of the hegemony of neoliberalism in the Western discourse of the last 30 years. Applied to education policy, realization of the principles of neoliberalism promotes free choice of school, liberalization of education legislation, entrepreneurial model of school management, decentralization of schools and increased freedom for schools in preparation of training programs. On the other hand, neoliberal approach in education policy increases standardization and subordination (Naumanen, Leppänen, Rinne, 2008) which are supposed to counterbalance the de-centralization tendencies. The end of the epoch of standardization and subordination and the beginning of the new epoch of post-standardization were predicted by some characteristic signs (Hargreaves, 2008), nevertheless, under the global-scale pressure towards increased unification, intellectual colonization and standardization have deeply penetrated all the spheres of human activity, including education (Autio, 2009; Autio, 2011).

According to E.V. Grunt (2017), in Russia, "the policy of "cultural imperialism" and "intellectual colonialism" of the United States and the western countries has, in the modern conditions, literally "swamped" the national higher education which results in erosion of staff potential" (Grunt, 2017). Transferring of overseas experience to Russian higher education institutions without taking into account the particularities of the national higher education system leads to blurred boundaries of scientific knowledge, formalized pedagogical activity, and its evaluation by controlling bodies. Adhering to the principles of formal rationality and thus allowing quantitative evaluation overwhelmingly prevail over qualitative undercuts the national education system. The time that the faculty spends on preparing documentation support of the educational process is comparable to the time spent on communication with students in the classroom, at lectures and seminars. The faculty start prioritizing publication requirements over educational-methodical and communicational ones as the university, regardless its type or orientation aspires to strengthen its position in the ratings.

\subsection{Intellectual capital}

Intellectual capital is a layer of people commanding the knowledge which is able to strengthen the country's economic indicators, ensure its political stability. However, applying knowledge requires a suitable cultural medium in which people are ready and willing to collaborate with each other. In the light of neoliberal principles of global education, it is, on the one hand, necessary to respect the rights of the individual in an open-minded society - namely, the person's right to choose a university to continue education. On the other hand, national education systems are obliged to maintain national cultural traditions. Apart from moral and ethical standards of behavior, the latter include specifics of the historically formed economic relations and scientific views. The importance of learning and generating new knowledge means the development of intellectual capital either within the framework of the national culture or abroad.

Nevertheless, in combination with the growth of globalization, today's higher education has stepped beyond the national boundaries and received greater freedom and independence from traditional state requirements. This has allowed to reconsider traditional views on the human rights in which the values of a globalized society.l have become dominant. In this context, individual free choice is highly conditional, since it is maneuvered by international structures and values, shaped by western specialists. National interests are practically left out of consideration - and, it is if at some point those clash with the promoted standards that the danger of intellectual colonization becomes real.

M.Á. Morales (2007) notes an interesting paradoxical tendency: leaning on globalization-dictated test standards, organizations search for better practices around 
the world completely overlooking the treasure of knowledge and know-how right under their noses, in the bright minds of their own people which conform to the unique, labor activity structures, shaped for centuries by the specifics of historydetermined commitments. The paradox of globalization is that, ironically, it is much easier to compare what you have with what the outer world makes compulsory and imposes on you than to reasonably prove the advantages of your own achievements and practices to the world which is indifferent to them.

\section{Materials and Methodology}

\subsection{Methodological bases of studying intellectual colonialism}

From the point of view of sociology of education, there are several scientific concepts which can serve as a theoretical background of researching intellectual colonialism.

Firstly, it is the law of "objectivizing" knowledge into an ideology which, in the global context, means domination of the ideology maintained in the universities of the countries leading on the global market. This ideology forms economic and political values which do not take national interests into account and may, moreover, contradict them (ideas of K. Mannheim).

Secondly, it is the Marxist concept of the theory of social reproduction put forward by L. Althusser who has proved that educational institutions are a part of the state ideological apparatus which helps reproduce the leading ideology through the educational plan.

Analyzing works in sociology of education, F.L. Pincus (2002) revealed the fact that property and control over large capitals on the part of the privileged social layers is, to a great extent, based on variations of the noneducational factor - for instance, on inheritance. In the conditions of globalization, global education inculcates the ideology of the privileged layers who control financial, economic and political resources.

Thirdly, it is the law of reproduction of the culture of the educational institution according to which, regardless of the student's cultural background, in the process of studying he assimilates the ethical, moral and ideological norms taught by this particular university - in our case, by this particular global system of higher education (ideas of P. Bourdieu).

Fourthly, it is the law of constructing reality which is based on the psychology of perception of the world, i.e. how we see the world, how we create and project it (ideas of A. Shütz, P. Berger, and T. Luckmann). In this case, ideology imposed by the global society transforms national ideology, gradually erasing its specifics and uniqueness which, for the affected states, leads to a risk of intellectual dependence.

\section{Research and Discussion}

\subsection{Tactics of colonial subjugation}

For African countries where there was no established national education systems, these tactics included developing local education system in the former colonizer's language paired with the policy of restraining and limiting this development to keep it on the level of secondary vocational training. S.H. Alatas (2000) has singled out the main traits characteristic of any imperialism, including intellectual one: exploitation, guarding, conformity, secondary role, intellectual rationalization, imperialistic rulers. He notes that, in the past, training colonial populations in certain technical spheres was deemed useful for the imperialistic governments. As a continuation of this policy in the modern underdeveloped regions including Malaysia and Singapore, dependence in the sphere of education was formed. "If you want to get a good degree you must enter European or American universities. If you want to know something you must read their books. This idea of dependence through intellectual guarding was accepted by default. It was assumed that people who lived in those territories knew less than

XLinguae, Volume 11, Issue 2, April 2018, ISSN 1337-8384, eISSN 2453-711X 
those who lived in the West. Likewise, before, it had been assumed that the colonies were unable to support themselves and could not be granted independence because, if they started self-governing, they would ruin the country. Underdeveloped countries had no technical know-hows and thus could not ensure their economies' development. Now, in the context of intellectual colonialism, they have no intellectual know-hows. Hence the necessity of a form of indirect guarding" (Alatas, 2000).

The practice of teaching various disciplines in African universities by RUDN alumni in the 70-80s confirms the words of S.H. Atalas (2000). Depending on whose colony a country had been, the entire learning process was organized to mimic that in universities of the colonizer (Great Britain, France, Portugal, Spain etc.). All the textbooks were used in the languages of these countries and, correspondingly, were written by western authors and published in the West.

As for other traits of imperialism, exploitation means collecting traditional knowledge from the semi-literate population with the purpose of subsequent processing and publishing the information abroad, making it property of the general public, while depriving the native carriers of this knowledge of economic dividends.

Conformity stands for assimilation of the behavioral culture in the image and likeness of the culture of the dominating country.

Secondary role in relation to the dominating countries is assigned the subjugated societies in all the spheres of popular activity, including the national education system system.

Intellectual rationalization is an attempt to explain imperialism as a necessary step in the progress of humanity, and the mission of imperialistic power - as civilizing people by making them its subject. The entire education system of the dependent countries works for this ideology.

Imperialistic rulers stands for more often than not mediocre people who used to be appointed governors in the dependent countries. Speaking of Malaysia and Singapore, S.H. Atalas (2000) quotes a civil servant Thomson as remarking that many of those who came from England were not exactly the cream of the British society. People who went to work in the colonies were not able to find a job in England and, if the had found one, they would have not achieved any career growth as they would have not been able to do the work on the appropriate level. This, among other instances, concerns today's visiting faculty members of national universities.

Tactics of intellectual colonization for Eastern European countries and Russia where there has always been a historically determined, developed national education system, consisted of destroying the national systems and subjecting them to the uniform global system based on on the culture and principles of certain countries (primarily US and Britain which lead in the ratings and concentrate financial streams in the sphere of education). All the former USSR republics unconditionally adopted the Bologna system in the most rigid forms while overlooking the fact that the suggested forms are of a framework nature. The developed Scandinavian countries, on the contrary, decided not to destroy their national systems. Instead, they made use of that same principle of the framework and presented evidence of conformity of their national education levels to the standards suggested by the Bologna Process.

For countries with a highly developed economy and stable politics like Japan, colonization tactics involve undermining the authority of the national education system through the global ratings. Japanese universities are primarily evaluated on the level of the Asian Pacific region where they do not occupy the highest positions. For example, according to the Times Higher Education rating, The University of Tokyo (Japan) occupies the 1st place in the Asia Rank, while in the World Rank it is on the 23rd; according to Quacquarelli Symonds (QS), the same university holds the 3rd place in the Asia Rank and the 31st in the World Rank. Similarly, in the Times Higher Education rating, University of Tokyo (Japan) holds the 7th place in the Asia Rank and the 52nd in theWorldRank, while in the database 
of Quacquarelli Symonds (QS) it holds the 5th place in the Asia Rank and the 36th in the World Rank. According to Times Higher Education, Tsukuba University (Japan) does not enter the top 10 universities of the Asia Rank, while according to Quacquarelli Symonds (QS), it occupies the 9th place in the Asia Rank.

Besides, the Japanese government is not so much concerned about these ratings being perceived as an index of the current academic and scientific potential of the Japanese universities, as about their being interpreted as a kind of evaluation of the national power and social viability of the state.

Professor Yukimasa Hayata (The Japan News by The Yomiuri Shinbun (http://www.yomiuri.co.jp/adv/chuo/dy/education/20141127.html) notes that the Japanese government has constitutionally guaranteed autonomous freedoms to the Japanese universities in regards to education and research. However, forced to compete on the education services market based on the freedom of economic activity, the Japanese universities have to reconsider these principles of autonomy. They are obliged to meet the international requirements thus losing their independence. They must be regularly accountable to the international organizations (according to whose databases international ratings are drawn up) about improvements in social and economic indicators of the university's development; about fulfilling the students' requirements; about maintaining the university's uniqueness reflected in its mission; they must systematically submit internal quality evaluations etc. The Japanese government, in its turn, has to work out policies of gifted students' selection; of recruiting foreign specialists to ensure high professionalism which will guarantee growth and economic recovery of the Japanese society.

L.A. Vasilenko (2017) stresses that the essence of intellectual colonialism is the combination of bi-directional processes. On the one hand, withdrawal of finances for extracting raw materials is arranged through virtualization of financial flows. On the other hand, intellectual resources are pumped out by means of arranging the global market of intellectual resources. The latter includes two groups of mechanisms:

1. The group of direct pumping out of intellectual resources to the territory of the metropolitan power:

a) systems of competitive relations paired with corruptogenic rating systems,

b) arranged "brain drain" and directed streams of intellectual migration, i.e., direct withdrawal of human capital,

c) arranged scientific research works directly on the colonial territories at the expense of low value of intellectual workers in the colonized countries,

d) low-cost buying up of inventions, technical innovations, and patents by making use of legal illiteracy of the population as regards drawing up invention patents on the international level; intellectual property on the territory of the metropolitan state is, meanwhile, strictly protected.

The group of mechanisms aimed at lowering the qualitative level of human capital on the neocolonial territory includes:

a) established inequality on the global market of intellectual resources,

b) instruments of lowering the level of education,

c) technologies aimed at cultural degradation of the neocolonial population,

d) flexible instruments of manipulating collective consciousness, including powerful support of mass media.

Intellectual colonization is manifested in the psychological pressure applied by global professional societies orienting young people to career growth. A lot of fast-and successful-career-growth-orienting literature is released domestically and abroad, e.g.:

Stress-Free Career by N.V. Samoukina, Successful Professional Career by Kornienko O.Y., The Success Process Handbook by Tony Fielek etc.

K. Caprino (2011) calls these strategical reference points "the myth of career bliss". She argues that these strategies are deceitful and harmful, leading people away

XLinguae, Volume 11, Issue 2, April 2018, ISSN 1337-8384, eISSN 2453-711X 
from realizing the necessity of taking tough action to eliminate the root causes which hinder life strategy and career growth.

According to A.V. Merenkov (2017), such illusions allow to, firstly, maintain the stability of the system in which only a small part of individuals quickly climbs the career ladder, usually with the aid of relations and acquaintances. Secondly, they allow to reproduce and intellectually reinforce the hierarchical relations of the economic and political elite by constantly urging those who are capable of scientific discoveries, technological innovations, and theories of social transformations to do active work in favor of the minority who exploits their talent to maintain its own preponderant position. The majority of those who constitute the main part of this disguised system of intellectual colonialism are not aware of its existence.

\subsection{Factors overtly or latently affecting formation of intellectual colonization}

International ratings create conditions of universalization and "cosmopolitanization" of the scientific thought - one of them is mandatory publications in the world leading journals.

Under the influence of the world ratings, the politics conducted by the ministry of education and science in the last ten years has led, according to V.V. Petrov (2017), to a change in the structure of Russian science. This is manifested in the state's aspiration to transfer scientific research from the sector of science to education (similarly to the western models of development). During the last 13 years, the amount of scientificresearch institutions has practically halved (from 2686 in 2000 to 1719 in 2013). Simultaneously, the amount of higher education institutions conducting scientific research has doubled (390 and 671 respectively). It is, however, impossible to blindly copy foreign schemes and specimens in order to plant them in the Russian soil - torn out of the socio-cultural context, even the best models which have shown their efficiency in the conditions of western societies, prove unworkable in the Russian realia. Thus, in October 2015, having drawn intermediate results of the 5-100-2020 program created in 2012, according to which five Russian universities are supposed to enter the world top 100 education ratings by 2012, president of Higher School of Economics Yaroslav Kuzminov admitted that by 2020 only MSU would be able to enter the world top 100, while the rest "stand practically no chance".

In this connection, the higher education institutions taking part in this program were urged to focus on the world sectoral ratings - it turned out that there, the position of Russian higher education establishments was much higher.

Financial dependence of the systems of higher education on the global leaders means investment flows into scientific projects (dependence on the international grants, as not all economies are able to compete with the economically developed countries). This became especially relevant in 1995, after the WTO had adopted the General Agreement on Trade in Service, where university education was positioned as a service subject to the rules of free trade. This agreement is also aimed at motivating strategical investments in order to create a favorable investment climate for universities. According to this treaty, in the conditions of globalized university education, evaluation of granted education services acts as a guarantee of economic freedom and receiving investments in higher education. This evaluation is effected on the basis of the rules established by the international structures. This is the clause that acts as the focus for distributing strategical investments among the developed countries (Alatas, 2000).

Universalization of the higher education in the conditions of intellectual imperialism is effected in a dichotomous mode: enforcement of the principle of the "equal, not differing" (McLennan, 1989); the prestige of being acknowledged by the global society on the background of the threat to academic independence and integrity; tolerance and respect for different cultures and religions ensuring equality of possibilities, however, some forms of this relativism - those like extremism and 
religious fundamentalism turn out to be incompatible with the main policy; contradictions in the scientific circles between freedom of speech and thought and concrete professionally relevant skills, values and knowledge (Harris, Helen, 2004).

Flexible, movable academic plans requiring constant renewal of disciplines (destroying the logic of assimilation of scientific information as well as the principle of fundamental knowledge; forming informational thinking).

Canadian researchers A. Harris and M.F. Helen (2004) studied colonization through pedagogy, methods, educational programs and knowledge in order to reveal the potential for collaboration between developing and developed countries in generating knowledge for the former. They analyzed a five-year experiment of supposedly liberating learning methods conducted in African, Asian and Caribbean countries. The research of realization of the international, youth-oriented Commonwealth diploma conferring project (DYD) has shown that the supposed architecture of pedagogical relationship based on P. Freire's (1979) principles of pedagogy must, with the aid of intellectual and conceptual instruments, develop the ability to withstand the processes of intellectual colonization (Freire, 1970). As stipulated in the contract concluded on admission to the educational institution, students were asked to specify their own learning expectations - acquiring knowledge through conversation with the supervisors. According to P. Freire (1970) и D. Kolb (1984), the supervisors are assigned the role of assistants in learning, not conveyors of knowledge. However, faced with reality, these pedagogical ideals proved to manifest themselves in other ways. While in societies where the authorities do not distance themselves from the people, the liberating education model does reinforce resistance to colonization, in societies where the authorities are more distanced, supervisors cannot act as either intermediaries, or conveyors of knowledge, because they are perceived as "gurus who pass on their personal wisdom" (Hofstede, 1991). In this contest, as noted by A. Harris and M.F. Helen (2004), engaging the learner into generating knowledge by means of dialogue is impossible. The researchers conclude that the supposedly liberating model is applied to societies where its principles prove inapplicable, and, instead of educating the learners, it artificially imposes the culturally incompatible "liberation" (Freire, 1970). However, researchers note that in developed countries, too, the dialogue learning model stipulated in the admission contract and supposed to "cultivate independent, self-assertive students seeking opportunities to learn in order to demonstrate their academic and professional development" (Notley, 1999), is confronted with considerable resistance on the part of the students.

Thus, J. Atherton's (2004) studies of the contract system in Britain showed that the students tended to strongly resist the approach, their typical feedback sounding as "Just tell us what to do!"

Basing his conclusions on the opinions of some students and supervisors, C. Christian revealed an incompatibility between this concept of learning and the Eastern culture (as quoted in Harris, Helen, 2004). A. Harris and M.F. Helen (2004) observe that, taking into account their previous experience, many students are not prepared to take upon themselves responsibility for their own learning in the context of the liberating model.

Cultural cosmopolitanism is formed due to several factors. One of them is studying mostly in English which changes the bases of thinking. Educational practice is dominated by overseas-published textbooks written by leading authors, recognized by the global scientific community, carrying the globally admitted ideology in evaluating facts. According to R. Philipson, global domination of the English language leads to formation of a language hierarchy provoking extinction of other languages and deepening the global inequality.

N.G. Popova (2017) has singled out traits of using the English language for colonization purposes. Those can be justly applied in the analysis of scientific

XLinguae, Volume 11, Issue 2, April 2018, ISSN 1337-8384, eISSN 2453-711X 
communication as well. One of the traits is defined as lack of alternative, that is, being forced to learn English. Indeed, in science today (practically around the globe), knowledge of English has become not only the token of career growth, but also of simply retaining one's position because, in order to prolong his contract, a scholar or scientist must submit a list of publications in international databases. In other words, one could talk about an absence of free choice regarding the form of presentation of results of intellectual activity. The second trait of a colonizer-language is ousting other languages from the territory of its domination. Sadly, adoption by the Russian ruling elites of the "Bologna" course has led to doing away with teaching other foreign languages apart from English. German and French, formerly traditional for Russian education, are not anymore studied in Russian graduate schools (Popova, Kuznetsova, 2016).

To the best of the author's knowledge, a similar situation has formed in the educational systems around the globe. Hence follows the third trait - using the colonizer-language for ideological purposes, with it being forced into application on the peripheries to serve the political and economic interests of the "center". A good example is English publishing business the profitability of which is comparable to that of high-tech innovation companies. Thus, the profit of Elsevier publishing house amounted to $37 \%$ in 2014; that of Springer - to 35\% - compared to, e.g., BMW - $10 \%$ и Apple - 29\% (Holcomb, 2015). In 2016, the company Thomas Reuters announced the sale of the department in charge of presenting information in the scientific field; the cost of the deal amounted to the record 3,35 million dollars. In other words, we look at establishing financial oligarchies in the sphere e scientific publications, while any financial oligarchy inevitably subdues the means of ideological influence on the masses (Popova, 2017).

In his article "Intellectual Imperialism: Concept, Features, Problems", S.H. Alatas (2000) discusses the notion of superiority of the dominion-states fixated in the minds of the former colonies' populations. There is a wide-spread belief that valuable knowledge only comes from the West, and good books are only written in Western countries. The West, on the other hand, is not in the least interested in the ideas of Asian economists and philosophers. The very idea that Asian political scientists have contributed to the development of political science sounds absurd to their western counterparts.

According to S.H. Alatas (2000), very few Malaysian students are interested in studying Asian thinkers of the past. They would rather read Plato, Aristotle, Machiavelli and other modern western thinkers while ignoring Van An Shih, Ibn Khaldun, Risalah, Nehru. This choice is made subconsciously, proceeding from the guideline that nothing useful can be derived from the works of Asian, or other nonwestern thinkers. These inherited notions belong to the past, they are dust of history, although the decision to do so is prompted by the sense of inadequacy caused by ignorance of one's own traditions.

In his work, S.H. Alatas (2000) cites another characteristic effect of intellectual imperialism - intellectual imitation. Thus, describing historical events, western scholars lean on the ideology of their own states when evaluating those. As an illustration, S.H. Atalas (2000) cites the history of Singapore written by Thomas S. Raffles, a British statesman who served in a colonial administrative office. He was mostly concerned with the intrigue in which he was involved instead of covering the central matters, instrumental in the country's development. Following this tradition, modern Singapore historians choose subjects and methods outlined by the European scholars, instead of exploring topics based on the national knowledge of historiography. However, if a Singapore scholar attempts to go beyond the framework adopted by the western scientific community, there rises a question: who will read him, and where will he be published? (Alatas, 2000) 
Another factor of forming cultural cosmopolitanism is the culture of the universities reproduced by the students and "cosmopolitizing" them. Grounding this statement one could cite the research of the realization of the international Commonwealth youthoriented diploma-conferring program (DYD), where the educational program and accompanying published materials were elaborated by developed countries' scholars. The researchers noted that the topic of colonization within the framework of educational practice is relevant here - not because certain countries dominate, but because the values transmitted by the academic community within the framework of the Commonwealth program belong to the model of democracy and social justice originating from the western society. Such blind adherence to a uniform model of democracy, freedom, and equality leaves no room for any prospects (Harris, Helen, 2004).

Along the entire course of DYD studies, the students regularly correlate the international texts with their national, regional context. It is important that the central place in the Commonwealth DYD program is occupied by the concept of community as family. These values are inculcated in the system of distributing authority in the process of the student-supervisor correlation.

Internet studies. Distance learning today cannot anymore be perceived as just a geographical distance between the student and teacher. Practice compliments the geographical principle with a cultural and emotional distance which may have different pedagogical consequences. A. Harris and M.F. Helen (2004) note, for instance, that distance DYD education is effected in English regardless the geography of learning. This may clash with the culture, language, and nature of the learners' emotions (Harris, Helen, 2004).

Online education in Russia is especially heavily involved in the process of globalization and standardization.

Nevertheless, the leading Russian higher education institutions have succeeded in uniting with the purpose of creating a unique system of online education where the courses are available free of charge, and without formal prerequisites to the basic education level. The platform was created in 2015 by the "National Platform of Open Education" Association founded by the leading universities - MSU, SPbU, SPbSU, NUST "MISiS", NRU "HSE", MFTI, UrFU and ITMO. The total amount of courses hosted by the National Platform of Open Education in 2017 amounted to 140; the number of registered listeners approached 150 thousand persons, while on average one listener subscribes to 2-3 courses. The Internet site of the Platform is to be found at openedu.ru .

Replacing the phenomenon of "knowledge" with that of "information". As has already been pointed out, modern intellectual colonialism is, unlike the imperialistic colonialism of XIX- XX, realized in a new version - that of imperial colonialism. According to M. Hardt and A. Negri, the Empire exercises «governance» within its subservient space, indefinitely mixing the identities of once sovereign concepts, forming flexible, loose hierarchies, thus modeling a brand new system of coordinates, convenient for itself. It is "information" that has become the instrument of such a "clever" steering in the global world. Its value is rated above other forms of knowledge, while informational exchange has simply become a universal asset and consumers' item (Hardt, Negri, 2000).

Intellectual capital is formed by knowledge kept in people's heads and no modern means of conserving knowledge like the Internet can guarantee preservation of these treasures, as only the human mind is able to determine their value thus lowering the probability of losing this or that bit of knowledge. The stress modern higher education puts on generating new knowledge is often associated with the difficulty of transforming this knowledge into concrete actions. Putting information at the head of the bases of modern society we expose ourselves to an informational boom

XLinguae, Volume 11, Issue 2, April 2018, ISSN 1337-8384, eISSN 2453-711X 
(informational oversaturation due to an excess of redundant and useless information), while suffering from the increasingly acutely felt lack of knowledge. In the educational processes, transferring emphasis from receiving knowledge to the skill of working with information is promoted by formalizing evaluation of the student's as well as the supervisor's work. Drawn into the race for a good mark, the student is often not so much concerned with the real benefits of learning the subject for his future professional activity as with the number of points earning which will allow him to slip through the finals. A Russian professor's annual teaching load amounts to over 900 hours. Besides that, the core quantitative indicator of his work includes publishing activity, quotations rating, theses defending. As a rule, the professor has to attend to these tasks out of duty, often at the expense of his educational, pedagogical activity. The quality of research work suffers too, as the topics do not depend on the teaching researcher's real scientific interests but on the interests of the journals and the current problematic zones dictated by the grants. Thus, for both, students and teachers, the fundamentalism of knowledge is replaced with virtuoso information juggling.

\section{Conclusion}

Colonization problems are closely connected with establishment of cultural imperialism. Traditionally, these two social phenomena are associated with underdeveloped countries. However, intensive globalization processes have changed the principles of space perception. Imperialism is the result of an alliance of several countries which reshape the world in their own favor. A highly developed economy and prosperity of certain states cannot safeguard against being subjugated by this alliance.

Russian science and education which have held a prominent position in the world hierarchy since the times of the USSR aspire to preserve and augment their influence on the science and education market. It is clear that reaching this goal requires integration of Russian national system into the global educational system as well as overcoming the deficit of pragmatic-practical elements of education. That is why, for Russia, joining the Bologna agreements is a logical step toward this integration. However, if, for the European Union states, creating a uniform educational platform is an objective measure, then, for Russia, which doesn't form part of this economic and political alliance, the principles of unification should not be rigid, and the standardization - overwhelming. There is a threat of losing competitive advantages of the national education system without which the attraction of Russia as an exporter of educational services may considerably diminish. Moreover, unfolding of certain scenarios which are already underway may result in Russia's becoming an "intellectual colony" delivering European-Union-standard trained specialists overseas.

Exploring the problems of intellectual colonialism one becomes aware of the fact that the first scholars to have started discussing this phenomenon were representatives of the regions which had once been colonies of the western states.

The middle of the 20th century is marked by the processes known as neocolonialism. Breaking free from the political yoke has awakened the scientific thought of the former colonies. Thanks to the researchers from those regions, these problematics have contributed to the scholarly heritage and served as a background for analysis of the processes marking the beginning of the 21 st century.

The author of this article attempts to show how much the revealed features and particularities of intellectual colonialism and the resulting intellectual colonization described by the researchers from underdeveloped countries are reflected in the modern realia of the countries which consider themselves developed.

In this context, studying modern higher education acquires a new meaning and gives a new dimension to theoretical and empirical research. There emerges a new thematic 
block for scholarly discussion. The threat of intellectual colonialism does not only mean economic, political and cultural subjugation. It leads to the colonized states' losing their national identity, as it reinforces global cultural "cosmopolitanization" processes and prompts gradual extinction of non-resisting nation-cultures.

\section{Acknowledgements}

The publication has been prepared with the support of the "RUDN University Program 5-100".

\section{Bibliographic references}

ALATAS, S.H. 2000. Intellectual Imperialism: Definition, Traits, and Problems. In: Southeast Asian Journal of Social Science, vol. 28, n. 1, pp. 23-45. ISSN 1568-4849, 1568-5314.

ATHERTON, J. 2004. Learning Contracts. Available online: http://www.dmu.ac.uk/ james-a/teaching/learning_contracts.htm

AUTIO, T. 2009. From Gnosticism to Globalization: Rationality, Trans-Atlantic Curriculum Discourse, and the Problem of Instrumentalism. Boston: Sense Publishers. ISBN 978-90-8790-763-1, ISBN 978-90-8790-764-8.

AUTIO, T. 2011. Eesti Inimarengu Aruanne. Inimarengu Balti rajad; muutuste kaks aastakümmet, edited by M. Lauristin. Tallinn: Eesti Koostöö Kogu. ISBN 1406-5398.

CAPRINO, K. 2011. The Myth of Career Blis. Available online: https://www.forbes.com/sit-es/85broads/2011/06/25/the-myth-of-career-

bliss/\#22ac4792518d

DAMM, K. 2015. National Answers to Global Challenges: An Example of Faculty Employment Regulation at Public Universities in Brazil and Germany. In: The national education system: under the influence of globalization and neoliberalization. Tula: TSU Publishing House. ISBN 978-5-7679-3059-3.

Freire, P. 1970. Pedagogy of the Oppressed. Harmondsworth: Penguin. ISBN 0-82641276-9.

GRUNT, E.V. 2017. Russian Professors' Activity and Assessment Thereof in the Conditions of Intellectual Colonialism in Global Educational Market. In: Intellectual colonialism on the global education market: Moscow: RUDN. ISBN 978-5-20907481-6.

HARDT, M. - NEGRI, A. 2000. Empire. Cambridge, Massachusetts London: Harvard University Press. ISBN 0674251210.

HARGREAVES, A. 2008. The coming of post-standardization: three weddings and a funeral. New York: Routhledge. ISBN 0415431085.

HARRIS, A. - HELEN, M.F. 2004. Intellectual Colonialism or Liberatory Education? An Exploration of Adult Education in an International Context. In: Paper presented at AERC 45th annual research conference, Canada. Available online: http://www.adulterc.org/applicatio-ns/ClassifiedLis...

Hofstede, G. 1991. Cultures and Organisations. New York: McGraw Hill hooks. ISBN 9780071439596, ISBN 0071439595.

HOLCOMB, A. 2015. Scholarly Publisher Profit Update. Available online: URL: https://alexholcombe.wo-rdpress.com/2015/05/21/scholarly-publisher-profit-update/

KING, R. 2011. Globalization and Higher Education. London: Centre for Higher Education Research and Information. Available online: http://www.open.ac.uk/cheri/documents/Lookingbackandlookingforward.pdf

Kolb, D. 1984. Experiential Learning. New Jersey: Prentice Hall. ISBN 0132952610.

LOOGMA, K. - MERIL, U. 2015. Educational changes: the adoption of standardizing/neoliberal reforms. Tula: TSU Publishing House. 123-148. ISBN 978-57679-3059-3.

XLinguae, Volume 11, Issue 2, April 2018, ISSN 1337-8384, eISSN 2453-711X 
MCLENNAN, G. 1989. Marxism Pluralism and Beyond. Cambridge: Polity Press in association with B. Blackwell. ISBN 9780745603506.

MOISEENKO, Yan.Yu. 2017. Resources and Instruments of Intellectual Colonialism: Introduction to Theoretical Analysis. Moscow: RUDN. ISBN 978-5-209-07481-6.

MORALES, M.Á. 2007. Knowledge Creation and Intellectual Colonialism. Available online:

http://www.qbsteam.com/index.php?src=news\&srctype=detail\&category=Articles\&re fno $=540$

NAUMANEN, P. - LEPPANEN, R. - RINNE, R. 2008. Euroopa Liidu muutuv hariduspoliitika. Tallinn: TLÜ Kirjastus. ISBN 978-9949-463-20-6.

NOTLEY, M. 1999. “Tutor's Manual.” London: Commonwealth Secretariat. ISBN 978998558560.

PETROV, V.V. 2017. The Social Leadership of the University under the Conditions of Changing Intellectual Standards. In: Intellectual colonialism on the global education market. Moscow: RUDN. ISBN 978-5-209-07481-6.

PINCUS, F.L. 2002. Sociology of Education: Marxist Theories. London: RoutledgeFalmer. ISBN 0-815-31615-1.

POPOVA, N.G. - KUZNETSOVA, L.B. 2016. English in postgraduate study of the 21st century: a posse ad esse. In: Higher education in Russia, vol. 5, pp. 42-49. ISSN 0869-3617.

POPOVA, N.G. 2017. Communicative Instruments of Linguistic Imperialism. Moscow: RUDN. ISBN 978-5-209-07481-6.

ROYON, R. - RAHWIDIATI, D. 2013. Beating the odds: locally relevant alternatives to world-class university. Singapore: ISEAS Publishing. ISBN 978981 4515047.

SUNARTO, K. 2015. The Indonesian System of Higher Education, Global Challenges and Domestic Contestation. Tula: TSU Publishing House. ISBN 978-57679-3059-3.

TAHSIN, H. 2007. Imperialist Democracy, Intellectual Colonialism. Available online: http://www.arabnews.com/node/295975

VASILENKO, L.A. 2017. Intellectual Colonialism: The Globalization Imperatives of Education and Science. Moscow: RUDN. ISBN 978-5-7679-3059-3.

Words: 7272

Characters: 50229 (27,90 standard pages)

Assoc. Prof. Svetlana A. Sharonova, Doctor of Sociology

Deputy of the Director for Research of the Institute of Foreign Languages

RUDN University (Peoples' Friendship University of Russia)

6 Miklukho-Malkaya Str.

117198 Moscow

Russia

s_sharonova@mail.ru

Assoc. Prof. Nina V. Trubnikova, PhD in Philosophy

Chair of Department of Advertising and Business Communication

RUDN University (Peoples' Friendship University of Russia)

6 Miklukho-Malkaya Str.

117198 Moscow

Russia

ninavadimovna@mail.ru

Assoc. Prof. Natalya S. Erokhova, PhD in History

Chief Specialist for Scientific and Innovation Development 
of the Institute of Foreign Languages

RUDN University (Peoples' Friendship University of Russia)

6 Miklukho-Malkaya Str.

117198 Moscow

Russia

erokhovanat@gmail.com

Assoc. Prof. Helena A. Nazarova, Doctor of Sociology

Department of Public Relations and Media Policy

The Russian Presidential Academy of National Economy

and Public Administration

84, Prospect Vernadskogo

119606 Moscow

Russia

helena_nazarova@mail.ru 